\title{
Plasma Lp(a) Concentration Is Inversely Correlated with the Ratio of Kringle IV/Kringle V Encoding Domains in the Apo(a) Gene
}

\author{
Dov Gavish, Neal Azrolan, and Jan L. Breslow \\ Laboratory of Biochemical Genetics and Metabolism, The Rockefeller University, New York 10021
}

\begin{abstract}
Plasma Lp(a) levels correlate with atherosclerosis susceptibility. This lipoprotein consists of an LDL-like particle attached to a large glycoprotein called apo(a). Apo(a) is a complex glycoprotein containing multiple Kringle domains, found to be highly homologous to plasminogen Kringle IV, and a single Kringle domain homologous to plasminogen Kringle V. Lp(a) levels appear to be inversely correlated with apo(a) size in a given individual. In this study, we have used probes specific to the Kringles IV and V domains of apo(a) CDNA in quantitative Southern blotting analysis. By this method, we have determined the ratio of Kringle IV/Kringle $V$ encoding domains in the apo(a) gene of 53 unrelated individuals with different

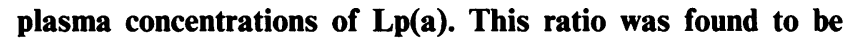
inversely correlated with $\log \mathrm{Lp}(\mathrm{a})$ levels $(r=-0.90, P$ $<0.0001)$ and directly correlated with apo(a) apparent molecular weight $\left(M_{\mathrm{r}}\right)(r=0.79, P<0.0001)$. In summary, by showing that $L p(a)$ concentrations and apo(a) apparent size are highly correlated with the ratio of Kringle IV/Kringle $V$ encoding domains in the apo(a) gene, we provide a DNA marker for this atherosclerosis risk factor as well as an important insight into the genetic mechanism regulating $L p(a)$ levels.
\end{abstract}

\section{Introduction}

$\mathrm{Lp}(\mathrm{a})^{1}$ is an LDL-like particle with a large glycoprotein called apo(a) attached to its apo B moiety through a disulfide bond $(1,2)$. Plasma $L p(a)$ concentration varies among people from 0.2 to $200 \mathrm{mg} / \mathrm{dl}$. Levels above $20-30 \mathrm{mg} / \mathrm{dl}$, present in 25\% of the population, have been associated with an increased risk of atherosclerotic disease $(3,4)$. The apo(a) protein apparent molecular weight $\left(M_{\mathrm{r}}\right)$ is estimated to be between 300 and 900 $\mathrm{kD}$, and in a given individual there is an inverse relationship between apo(a) size and plasma $\operatorname{Lp}(\mathrm{a})$ concentration (5). Apo(a) is highly homologous to plasminogen $(6,7)$. Plasminogen structure consists of signal, tail, Kringles I through $\mathrm{V}$ and protease domains (8). Apo(a) contains the signal domain, lacks the tail and Kringles I through III, but includes a variable

Address reprint requests to Dr. Breslow, Laboratory of Biochemical Genetics and Metabolism, The Rockefeller University, New York, NY 10021.

Received for publication 28 March 1989 and in revised form 5 September 1989.

J. Clin. Invest.

(C) The American Society for Clinical Investigation, Inc.

$0021-9738 / 89 / 12 / 2021 / 07 \$ 2.00$

Volume 84, December 1989, 2021-2027 number of Kringle IV-like domains, a single copy of Kringle $\mathrm{V}$ and the protease domain $(6,7)$. There is evidence that different apo(a) alleles code for proteins with different numbers of Kringle IV repeats (5-9). Based on the range of apo(a) $M_{\mathrm{r}}$ $(300-900 \mathrm{kD})$ and the size of each Kringle IV $\left(M_{\mathrm{r}}-12.7 \mathrm{kD}\right)$, one can estimate that any given apo(a) may contain between 15 and 40 Kringle IV repeats.

The apo(a) and plasminogen genes are closely linked on the long arm of chromosome 6 (q 26-27) $(10,11)$. In a family study, a restriction fragment length polymorphism (RFLP) ${ }^{1}$ of the plasminogen gene was shown to be tightly linked to the apo(a) size phenotype and the plasma $L p(a)$ concentration (12). These results suggest that genetic variation at the apo(a) gene locus controls apo(a) size and Lp(a) levels. In this study, we show that the variable number of Kringle IV-like domains encoded by the apo(a) gene is the main factor determining the size of the apo(a) protein and the plasma $\mathrm{Lp}(\mathrm{a})$ concentration.

\section{Methods}

Subjects. Subjects consisted of individuals seen in the clinic of the Laboratory of Biochemical Genetics and Metabolism at The Rockefeller University. After being screened for plasma Lp(a) concentrations, 53 subjects (41 patients referred for diagnosis and treatment of lipoprotein disorders and 12 normal volunteers) with a wide range of Lp(a) concentrations were selected for participation in the study. Venous blood was drawn from the forearm and transferred to tubes containing sodium EDTA. Samples were immediately centrifuged at $2,000 \mathrm{~g}$ at $4^{\circ} \mathrm{C}$ for $15 \mathrm{~min}$, and 0.5 -ml aliquots of plasma were assayed for $L p(a)$ concentration and apo(a) size within $24 \mathrm{~h}$ or stored at $-70^{\circ} \mathrm{C}$ for further analysis. Storage under these conditions did not affect either measurement.

Measurement of $L p(a)$ concentration and determination of apo(a) phenotype. A polyclonal antibody to human $\mathrm{Lp}(\mathrm{a})$ was prepared in male New Zealand white rabbits. $\operatorname{Lp}(\mathrm{a})$ was isolated by sequential ultracentrifugation between densities 1.060 and $1.080 \mathrm{~g} / \mathrm{ml}$, followed by Sephacryl $400 \mathrm{HR}$ gel chromatography (13). After dialysis with 150 $\mathrm{mM} \mathrm{NaCl}$, animals were immunized with $100 \mu \mathrm{g}$ of $\mathrm{Lp}$ (a) protein in Freund's complete adjuvant and $4 \mathrm{wk}$ later were boosted with the same dose. After a subsequent 2-wk period, the animals were bled and partially delipidated rabbit antiserum was prepared. The immunoglobulin fraction was isolated using a protein-A column and fractionated by being passed over LDL, HDL, and albumin Sepharose columns (2). Antibodies cross-reacting with plasminogen or LDL were further absorbed extensively with both purified plasminogen and LDL until no further precipitation was observed. The anti $\operatorname{Lp}(a)$ antibody was free of cross-reactivity with plasminogen and LDL as detected by Ouchterlony analysis, Western blotting, and double tier rocket immunoelectro-

1. Abbreviations used in this paper: GAR-HRP, goat anti-rabbit IgG horseradish peroxidase; RFLP, restriction length polymorphism; TBS, Tris-buffered saline. 


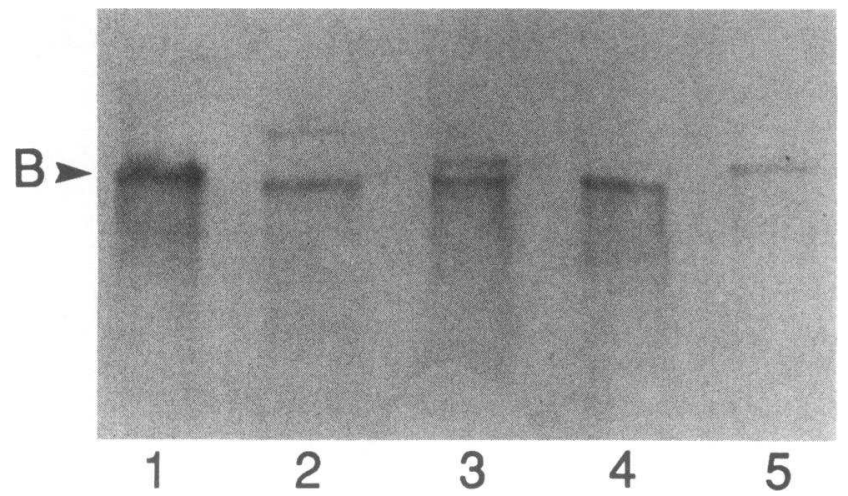

Figure 1. Demonstration of different apo(a) size phenotypes in individual plasma samples by immunoblot analysis. Plasma $(1.3 \mu \mathrm{l})$ was subjected to SDS-PAGE under reducing conditions in $3 \%$ to $12 \%$ gradient gels. Western blot analysis was performed as described in the text. Lane 1, B type; lane 2, B/S type; lane $3, \mathrm{~S}_{1} / \mathrm{S}_{2}$ type; lane 4 , $\mathrm{S}_{1}$ type; and lane 5, $\mathrm{S}_{2}$ type.

phoresis $(9,14)$. This monospecific antibody was used to quantitate $\mathrm{Lp}$ (a) levels by rocket immunoelectrophoresis (15). Special care was taken to ensure that the $\mathrm{Lp}$ (a) concentration in the plasma samples was in the linear range of the standards, which were applied on the same plate. One batch of standards was used throughout this study (Immuno AG, Vienna, Austria). Controls with high LDL and low LP(a) were used to verify assay specificity. All $L p(a)$ measurements were performed in triplicate and serial dilutions of every sample were made to ensure linearity of the assay. The coefficient of variation of the measurement was $<3 \%$. A pure antibody and series of controls supplied by Dr. G. M. Kostner were also used to verify our measurements.

Apo(a) isoform size was determined by SDS-PAGE of whole plasma and subsequent Western blotting as described by Utermann (9). Briefly, $10 \mu$ l of plasma was mixed with $250 \mu$ l of $5 \%$ SDS in $\mathrm{H}_{2} \mathrm{O} .5$ $\mu \mathrm{l}$ of $\beta$ mercaptoethanol and $10 \mu \mathrm{l} 1.5 \%$ bromophenol blue in glycerol were added, and the solution was boiled for $10 \mathrm{~min}$. Aliquots of $50 \mu \mathrm{l}$ were used for electrophoresis. A reference serum with known doubleband phenotype was included in each run. SDS-PAGE was performed according to Laemmli (16) in a 3-12\% gradient gel using a horizontal slab gel apparatus type SE 280 (Hoefer Scientific, San Francisco, CA).
The transfer of proteins to nitrocellulose filters was performed according to Towbin et al. (17) at $80 \mathrm{~V}$ overnight in a mini-cell blotting chamber (Bio-Rad Laboratories, Richmond, CA). Immunostaining was performed using the goat anti-rabbit-IgG horseradish peroxidase (GAR-HRP) assay kit (Bio-Rad Laboratories). The filters were preincubated with $3 \%$ gelatin in $20 \mathrm{mM}$ Tris, $500 \mathrm{mM} \mathrm{NaCl} \mathrm{pH} 7.5$ (TBS) and then incubated for $6 \mathrm{~h}$ with the rabbit anti-human $\mathrm{Lp}(\mathrm{a})$ antibody at a titer of $1: 200$ in $1 \%$ gelatin in TBS. Filters were then washed in TBS containing $0.05 \%$ Tween 20 for 20 min and incubated with a 1:2,500 titer of the GAR-HRP antibody for $2 \mathrm{~h}$. After washing for $20 \mathrm{~min}$, color was developed in $0.015 \% \mathrm{H}_{2} \mathrm{O}_{2}$. Examples of the observed size phenotypes of apo(a) are shown in Fig. 1. Apparent molecular weights $\left(M_{\mathrm{r}}\right)$ were estimated by comparing the migration of the bands to the migration of apo(B) and thyroglobulin standards.

Probe preparation, DNA isolation and Southern blotting analysis. Specific apo(a) riboprobes were prepared by subcloning double stranded DNA oligomers synthesized on a 381A DNA synthesizer (Applied Biosystems, Foster City, CA) into a pGEM1 plasmid (Promega, Madison, WI). The vectors were linearized with Hind III, and $T_{7}$-RNA polymerase was utilized for riboprobe synthesis with $\alpha\left[{ }^{32}\right.$ P $] U T P$. The riboprobe specific to the Kringle IV-like domain was $61 \mathrm{nt}$ long and corresponded to apo(a) cDNA bp 525 to 585 , as reported by McLean et al. (6). The riboprobe for the Kringle V-like domain was 63nt long and corresponded to apo(a) cDNA 12,806 to $12,868 \mathrm{bp}$ (6). The sequence for the Kringle IV probe was chosen so that it would be highly homologous (at least 94\%) to 34 of the 37 Kringle IV-like repeats described by McLean et al. (6). This probe was only $72 \%$ homologous with the plasminogen Kringle IV domain and $<42 \%$ homologous with other portions of the apo(a) and the plasminogen genes. The probe for Kringle $\mathrm{V}$ was $80 \%$ homologous to plasminogen Kringle V. The sequences of both probes are shown on Fig. 2. The riboprobe for $\gamma$ actin was 230nt long and corresponded to the Hind III/Xba I fragment of $\gamma$-actin cDNA clone PHF1 (18).

DNA was isolated from a 3-ml buffy coat preparation derived from $30 \mathrm{ml}$ of venous blood. The buffy coat was incubated overnight at $55^{\circ} \mathrm{C}$ in lysis buffer (20 mM EDTA; $1 \%$ sarcosyl; $0.2 \mathrm{M}$ Tris- $\mathrm{HCl}, \mathrm{pH}$ 8; $0.4 \mathrm{M} \mathrm{NaCl} ; 8 \mathrm{M}$ urea) including Proteinase $\mathrm{K}(1,000 \mathrm{U} / \mathrm{ml})$. The mixture was then incubated with RNase $A(13 \mu \mathrm{g} / \mathrm{ml})$ at $37^{\circ} \mathrm{C}$ for $2 \mathrm{~h}$. DNA was isolated with an Applied Biosystems 340A nucleic acid extractor. The DNA containing sample was loaded into the extractor vessels, extracted with phenol/chloroform $/ \mathrm{H}_{2} \mathrm{O}$ (35:35:30), and precipitated with ammonium acetate/ethanol, according to the manufac-

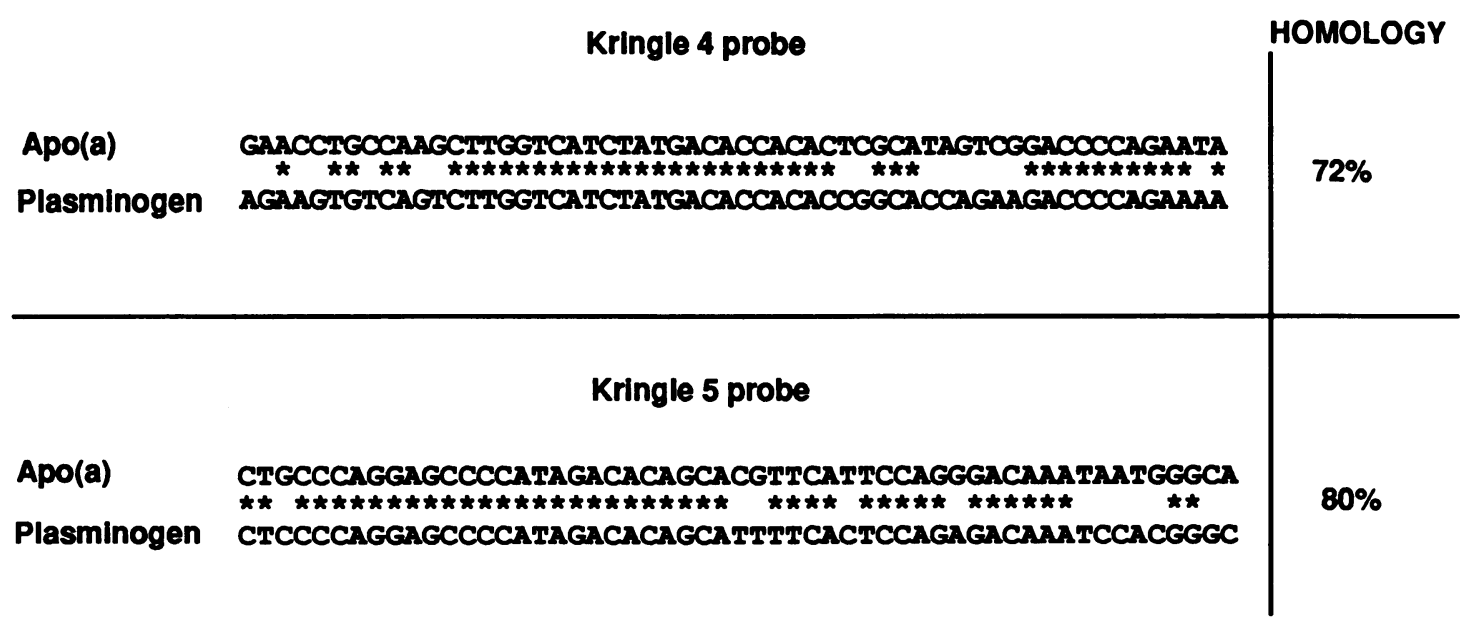

Figure 2. The nucleotide sequences of the Kringle IV and Kringle $\mathrm{V}$ probes used in this study compared with the homologous sequence in the plasminogen gene. The probe sequences are $<42 \%$ homologous with other structures in the apo(a) and plasminogen genes. 
Table I. The Lp(a) Concentration, Apo(a) Apparent Molecular Weight, and Kringle IV/ $\gamma$ Actin and Kringle IV/Kringle V Ratios of 41 Individuals with a Single Band Apo(a) Phenotype

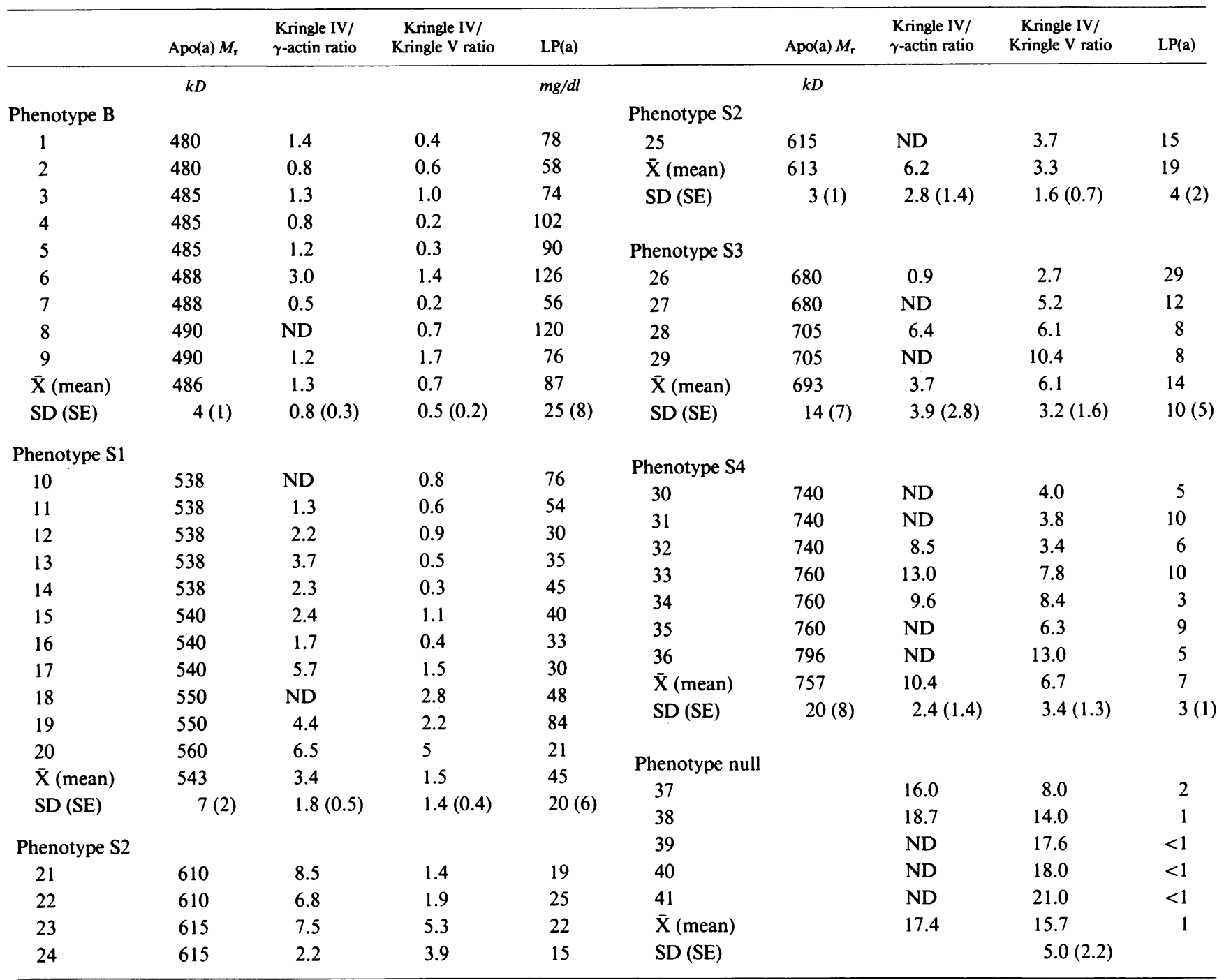

$\mathrm{Lp}$ (a) was measured using a monospecific anti $\mathrm{Lp}$ (a) antibody by rocket immunoelectrophoresis (15). Apo(a) $M_{\mathrm{r}}$ was estimated according to the methods described by Utermann (10) and Goubatz (20). KIV/KV and KIV/ $\gamma$ actin ratios were derived from scanning of the Southern blot films. The same control specimens were used on each blot to correct for variation in exposure time of the films. ND, not done.

turer's instructions. The DNA was then resuspended in $700 \mu \mathrm{l}$ of 10 $\mathrm{mM}$ Tris- $\mathrm{HCl}, \mathrm{pH} 8 ; 0.1 \mathrm{mM}$ EDTA. In preliminary studies, genomic DNA from two individuals with LP(a) levels of 2 and $80 \mathrm{mg} / \mathrm{dl}$ were digested with five restriction enzymes that do not cut the apo(a) cDNA. After Southern blotting the digested DNA was hybridized with the Kringle IV probe (19). The blot and the derived restriction map are shown on Fig. 3 and 4. In further experiments, DNA aliquots $(10 \mu \mathrm{g})$ from all study participants were digested with Xba I, electrophoresed through $0.8 \%$ agarose gels, and blotted onto nylon membranes. Blots were hybridized sequentially with each of the $\gamma^{32} \mathrm{P}$-labeled probes, washed, and exposed to $\mathrm{x}$-ray film. After each probing, blots were stripped with $0.5 \mathrm{M} \mathrm{NaOH}$ before rehybridization. Stringent washing conditions $\left(0.1 \% \mathrm{SDS}, 0.1 \% \mathrm{SSC}\right.$ at $\left.65^{\circ} \mathrm{C}\right)$ resulted in the detection of single bands with each of the two apo(a) probes used. The bands were scanned with laser densitometric scanner (LKB Instruments, Bromma, Sweden). The Kringle IV-like and Kringle V-like probes detected bands of 2 and $2.3 \mathrm{~kb}$, respectively. The $\gamma$-actin probe detected several bands of which a 2-kb band was scanned. The apo(a) Kringle $\mathrm{V}$ and $\gamma$-actin are presumably single copy in the haploid genome and are used as controls to correct for the amount of DNA loaded on each lane. The ratio of Kringle IV $/ \gamma$-actin and Kringle IV/Kringle V signals were used as a measure of the number of Kringle IV domain repeats in the apo(a) gene. These ratios were correlated with the apo(a) apparent molecular weight $\left(M_{\mathrm{r}}\right)$ and plasma $\mathrm{Lp}(\mathrm{a})$ concentrations.

\section{Results}

Table I shows the plasma $L p(a)$ concentration, apo(a) apparent molecular weight $M_{\mathrm{r}}$, and the Kringle IV $/ \gamma$-actin and Kringle IV/Kringle $\mathrm{V}$ ratios derived from the quantitative Southern blots for the 41 single band phenotype individuals studied. Table II shows the results obtained from 12 double band phenotype individuals. Fig. 1 illustrates the apo(a) size phenotypes observed. We have detected nine different apparent molecular weights for apo(a), which are similar to those described by Gaubatz et al. (20). However, some of these are quite similar 
Table II. Lp(a) Concentration, Apo(a) Apparent Molecular Weight, and Kringle IV/ $\gamma$-actin and Kringle IV/Kringle V Ratios of 12 Individuals with a Double Band Apo(a) Phenotype

\begin{tabular}{|c|c|c|c|c|c|c|}
\hline & Phenotype & $\begin{array}{l}\mathrm{Apo}(\mathrm{a}) \\
M_{\mathrm{r}}\end{array}$ & $\begin{array}{l}\text { Calculated } \\
\text { Apo(a) } M_{\mathrm{r}}\end{array}$ & $\begin{array}{l}\text { Kringle IV/ } \\
\gamma \text {-actin ratio }\end{array}$ & $\begin{array}{c}\text { Kringle IV/ } \\
\text { Kringle V ratio }\end{array}$ & Lp(a) \\
\hline & & $k D$ & $k D$ & & & $m g / d$ \\
\hline \multirow[t]{2}{*}{1} & B-S ${ }_{1}$ & 480 & 510 & 2.4 & 1.1 & 104 \\
\hline & & 540 & & & & \\
\hline \multirow[t]{2}{*}{2} & B-S $S_{1}$ & 480 & 510 & 1.2 & 1.0 & 73 \\
\hline & & 540 & & & & \\
\hline \multirow[t]{2}{*}{3} & B-S $S_{2}$ & 485 & 550 & 7.1 & 4.0 & 40 \\
\hline & & 615 & & & & \\
\hline \multirow[t]{2}{*}{4} & B-S 2 & 480 & 545 & 2.6 & 3.1 & 52 \\
\hline & & 610 & & & & \\
\hline \multirow[t]{2}{*}{5} & B-S $S_{3}$ & 488 & 584 & 5.6 & 1.4 & 58 \\
\hline & & 680 & & & & \\
\hline \multirow[t]{2}{*}{6} & B-S $S_{3}$ & 485 & 595 & 5.4 & 3.7 & 21 \\
\hline & & 705 & & & & \\
\hline \multirow[t]{2}{*}{7} & $\mathbf{S}_{1}-\mathbf{S}_{3}$ & 540 & 610 & 5.6 & 3.8 & 28 \\
\hline & & 680 & & & & \\
\hline \multirow[t]{2}{*}{8} & $S_{1}-S_{3}$ & 550 & 630 & 2.7 & 1.0 & 38 \\
\hline & & 705 & & & & \\
\hline \multirow[t]{2}{*}{9} & $\mathbf{S}_{1}-\mathbf{S}_{3}$ & 560 & 635 & 5.5 & 1.6 & 11 \\
\hline & & 705 & & & & \\
\hline \multirow[t]{2}{*}{10} & $\mathrm{~S}_{2}-\mathrm{S}_{3}$ & 610 & 660 & 6.9 & 6.0 & 10 \\
\hline & & 705 & & & & \\
\hline \multirow[t]{2}{*}{11} & $\mathbf{S}_{2}-\mathbf{S}_{3}$ & 610 & 645 & 8.6 & 7.5 & 12 \\
\hline & & 680 & & & & \\
\hline \multirow[t]{2}{*}{12} & $\mathrm{~S}_{2}-\mathrm{S}_{4}$ & 610 & 675 & ND & 6.2 & 8 \\
\hline & & 740 & & & & \\
\hline
\end{tabular}

Calculated $M_{\mathrm{r}}$ was derived from summation of both observed apparent $M_{\mathrm{r}}$ divided by two. Those calculated values were used for further analysis.

$\mathrm{ND}$, not done.

and, for simplicity and comparative purposes, we assigned the apparent molecular weights to six groups (B to S-4) as suggested by Utermann (5). Individuals with double allele phenotypes were given a molecular weight estimate derived by summing the two single allele phenotype apparent molecular weights and dividing by two. The apo(a) estimated molecular weight for each person studied is given in Tables I and II.

Genomic DNA from two individuals with low and high plasma $L p(a)$ levels was used to obtain a restriction map of the region coding for the Kringle IV domain. Southern blotting analysis using the Kringle IV probe (Fig. 2) with five different restriction endonucleases is shown in Fig. 3 and the derived restriction map is shown in Fig. 4. With each enzyme, a single major band was found with each of the DNAs used in this analysis. The intensity of the bands was much greater with DNA from the individual with low Lp(a) levels. Other, much weaker bands (up to two) were noticed with certain restriction endonucleases. Since none of the restriction sites were in the cDNA for apo(a), our observation implies a highly conserved and repeated restriction pattern in the introns adjacent to the regions coding for most of the Kringle IV-like domains of the apo(a) gene. Therefore, the variation in signal intensity with the Kringle IV probe is due to a different number of copies of the same size included in each chromosomal DNA. Each copy
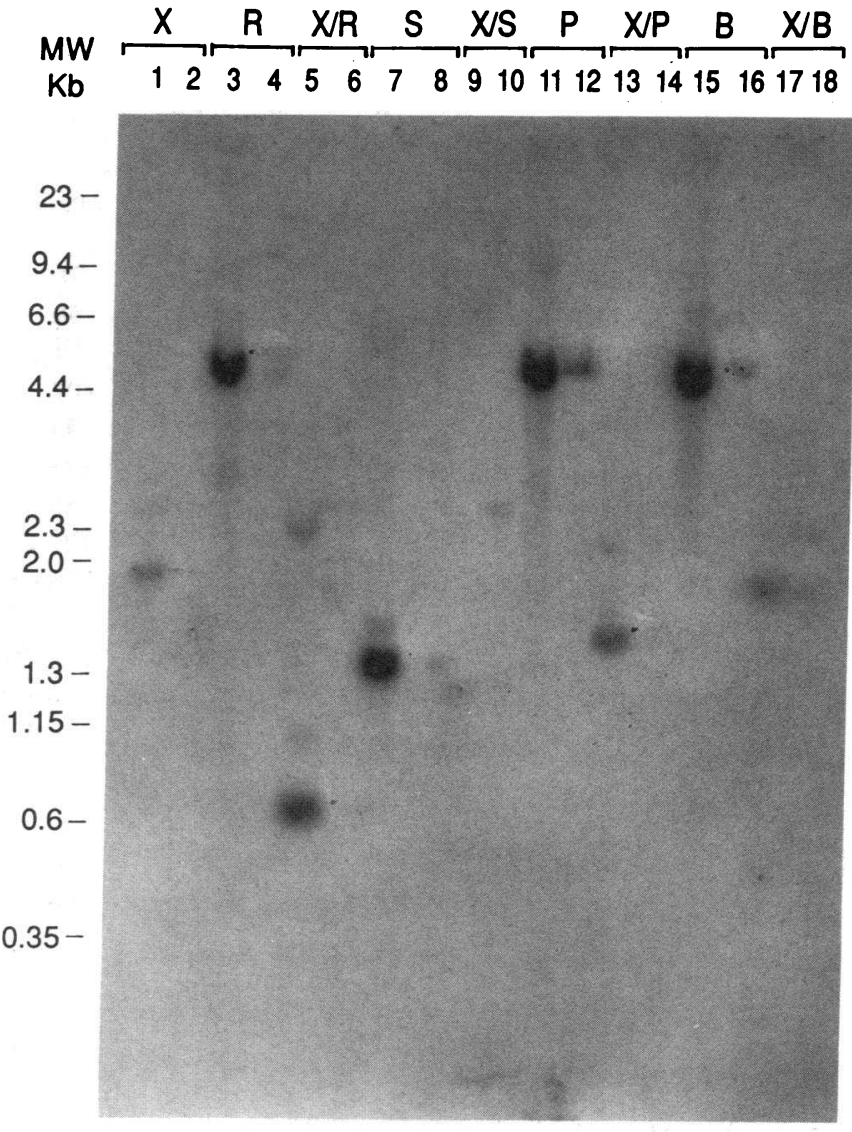

Figure 3. Genomic blotting analysis with the Kringle IV probe of DNA from an individual with low $\mathrm{Lp}(\mathrm{a}) 2 \mathrm{mg}$ /dl (lanes $1,3,5,7,9$, $11,13,15,17)$ and another individual with high $\mathrm{Lp}(\mathrm{a}) 80 \mathrm{mg} / \mathrm{dl}$ (lanes 2, 4, 6, 8, 10, 12, 14, 16, 18). Chromosomal DNA was digested with Xba (lanes 1,2$)$, Eco RI $(3,4)$, Xba I and Eco RI $(5,6)$, Sac I $(7,8)$ Xba I and Sac I $(9,10)$, Pvu II $(11,12)$, Xba I and Pvu II $(13,14) \mathrm{Bgl}$ II $(15,16)$, Xba I and Bgl II $(17,18)$. Southern analysis was performed by hybridization with the ${ }^{32} \mathrm{P}$-labeled Kringle IV probe. Molecular weight standards are: Hind III digested $\lambda D N A$ and Hae III digested $\phi$ X174 DNA (New England Biolabs).

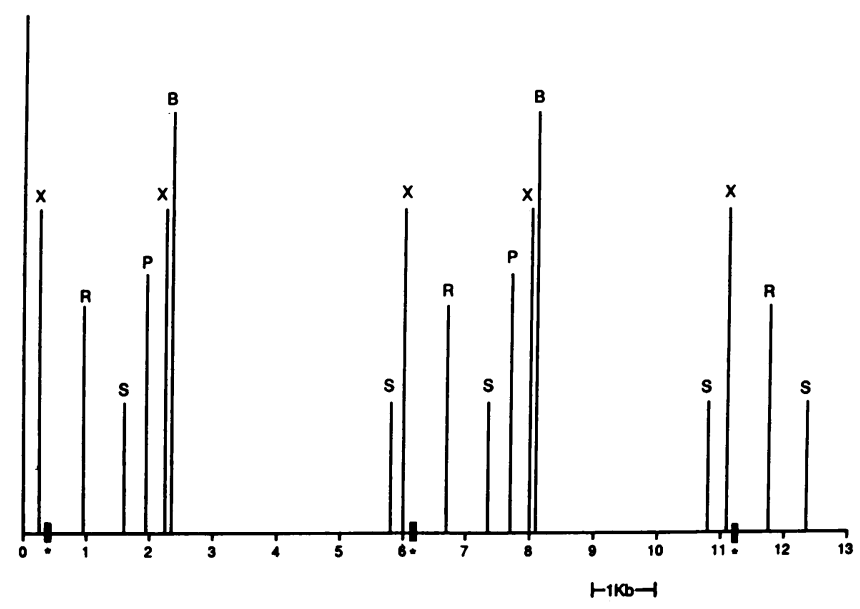

Figure 4. Restriction map of the genomic region coding for the apo(a) Kringle IV-like domains. The location of the sequence of the Kringle IV probe is shown by the solid box. Restriction sites are indicated as follows: $(X)$ Xba I, $(R)$ Eco RI, $(S)$ Sac I, $(P)$ Pvu II, $(B)$ Bgl II. *Location of the Kringle IV probe. 


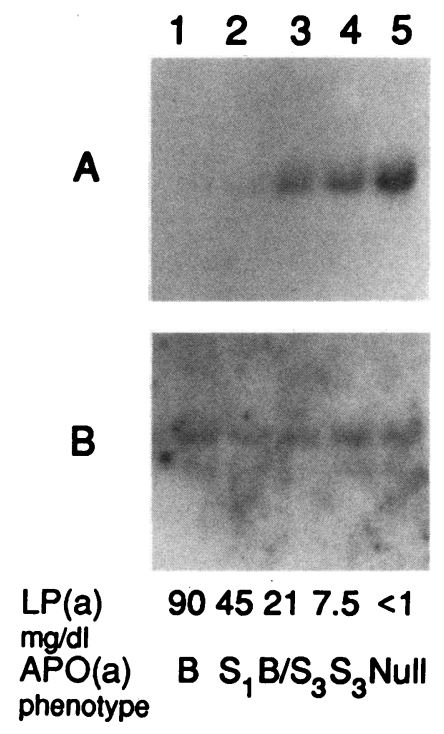

Figure 5. Quantitative Southern blotting analysis. Xba I digested DNA $(10 \mu \mathrm{g})$ from five individuals was Southern blotted and hybridized sequentially with the apo(a) Kringle IV probe $(A)$ and then with the apo(a) Kringle $V$ probe $(B)$. Between probings, membranes were thoroughly stripped. The corresponding Lp(a) concentration and Apo(a) size phenotypes were determined as described in Methods and are indicated.

presumably contains two or fewer Kringle IV domains judging from the size of the bands in the restriction analysis.

Fig. 5 shows the bands obtained after Southern blotting with probes to Kringle IV and Kringle $\mathrm{V}$, which were used to determine the Kringle IV/Kringle $V$ ratio of five patients with varying plasma levels of $\mathrm{Lp}(\mathrm{a})$. There is an obvious variation from person to person in the intensity of the signal from the Kringle IV probe, which is not seen with the Kringle V probe. In addition, the relative intensity of the Kringle IV signal correlates inversely with the plasma $\mathrm{Lp}(\mathrm{a})$ concentration and directly with apo(a) protein size.

Table III summarizes the correlation analysis of $\mathrm{Lp}(\mathrm{a})$ concentration, estimated molecular weights, and Kringle IV/ Kringle $\mathrm{V}$ and Kringle $\mathrm{IV} / \gamma$-actin ratios for all 53 persons

Table III. A Comparison of $L p(a)$ Concentration, Apo(a) Apparent Molecular Weights, and Kringle IV/Kringle V and Kringle IV/r-actin Ratios

\begin{tabular}{|c|c|c|c|c|}
\hline $\begin{array}{c}\text { Lp(a) vs. Apo(a) } \\
M_{\mathrm{r}}\end{array}$ & $\begin{array}{l}\text { Apo(a) } M_{\mathrm{r}} \text { vs. } \\
\mathrm{KIV} / \mathrm{KV} \text { ratio }\end{array}$ & $\begin{array}{c}\text { Apo(a) } M_{\mathbf{r}} \\
\text { vs. } \\
\mathrm{KIV} / \gamma \text {-actin } \\
\text { ratio }\end{array}$ & $\begin{array}{c}\text { Lp(a) vs. } \\
\text { KIV/KV ratio }\end{array}$ & $\begin{array}{c}\mathrm{Lp}(\mathrm{a}) \mathrm{vs.} \\
\mathrm{KIV} / \boldsymbol{\gamma} \text {-actin } \\
\text { ratio }\end{array}$ \\
\hline
\end{tabular}

\begin{abstract}
Linear correlation
\end{abstract}

$\begin{array}{llllll}\mathrm{R} & -0.80 & 0.79 & 0.85 & -0.61 & -0.64 \\ \mathrm{R}^{2} & 0.64 & 0.63 & 0.72 & 0.37 & 0.41 \\ P & 0.0001 & 0.0001 & 0.0001 & 0.0001 & 0.0001\end{array}$

$\log (X)-$ Linear correlation

$\begin{array}{llllcc}R & -0.92 & 0.78 & 0.77 & -0.90 & -0.85 \\ \mathbf{R}^{2} & 0.84 & 0.61 & 0.59 & 0.81 & 0.73 \\ P & 0.0001 & 0.0001 & 0.0001 & 0.0001 & 0.0001\end{array}$

Linear and $\log$ linear correlation analysis was done on the clinfo computer system. $\log (x)$ means that the first quantity in each of the comparisons was log transformed. Kringle IV/Kringle V and Kringle IV $/ \gamma$-actin ratios were derived from scanning of Southern blot films after using specific radiolabeled probes. Apo(a) $M_{\mathrm{r}}$ was estimated as described in the text. studied. The $\mathrm{Lp}(\mathrm{a})$ concentration was inversely correlated with the apo(a) apparent molecular weight $(r=-0.80, P<0.0001)$. The apo(a) apparent molecular weight was highly correlated with the Kringle IV/Kringle V and Kringle IV/ $\gamma$-actin ratios ( $r$ $=0.79$ and $r=0.85$, respectively, $P=0.0001)$. The $\mathrm{Lp}(\mathrm{a})$ concentration was inversely correlated with the Kringle IV/ Kringle $\mathrm{V}$ and Kringle IV/ $\gamma$-actin ratios $(r=-0.61$ and $r$ $=-0.64$, respectively, $P<0.0001$ ). $\log$ transformation of the $\mathrm{Lp}$ (a) concentrations improved the correlations with the apo(a) apparent size, and the Kringle IV/Kringle $\mathrm{V}$ and Kringle IV $/ \gamma$-actin ratios $(r=-0.92, r=-0.90$, and $r=-0.85$, respectively).

Fig. 6 illustrates the individual comparisons of apo(a) apparent molecular weight with $\log \mathrm{Lp}(\mathrm{a})$ concentration $(A)$, apo(a) apparent molecular weight with the Kringle IV/Kringle $\mathrm{V}$ ratio $(B)$, and the Kringle IV/Kringle $\mathrm{V}$ ratio with the $\log$ $\mathrm{Lp}(\mathrm{a})$ concentration $(C)$. The relationships are striking and persist throughout the entire range of values without discontinuity. It is of interest that individuals with very low to undetectable plasma $\mathrm{Lp}$ (a) concentrations, who might be considered to have null alleles, fall on the same line as the other individuals studied. Some of the variation observed in the Kringle IV/Kringle $\mathrm{V}$ and Kringle IV/ $\gamma$-actin signal ratios could be due to the presence of a null allele in some of the individuals with a single band phenotype, or due to variation in the hybridization of some of the Kringle IV domains to the probe.

\section{Discussion}

In the present study, we have used DNA probes specific to the Kringle IV and V domains of apo(a) in quantitative Southern blotting analysis to show that the number of Kringle IV encoding domains in the apo(a) gene correlates directly with apo(a) protein size and inversely with plasma $L p(a)$ concentration. The exact manner whereby this occurs is not yet resolved. However, individuals with apo(a) gene alleles containing a large number (40 or more) of Kringle IV repeats might possess little to no plasma apo(a) and $\mathrm{Lp}(\mathrm{a})$ by several mechanisms. For example, if each Kringle IV domain is encoded by a single exon, the apo(a) gene might be quite large. In this case transcription efficiency or processing of the primary transcript might be rate limiting in mRNA production. Alternatively, the size of the mRNA might cause instability or poor translation efficiency. Finally, the size of the protein may predispose to intracellular degradation, interference with secretion, or enhanced extracellular catabolism. Increased intracellular catabolism of large proteins has previously been proposed by Goldberg and St. John (21). In addition, Bersot et al. have reported that in individuals with two sizes of apo(a), the larger one associates with postprandial triglyceride-rich chylomicron remnants (22). This might provide a mechanism for the additional clearance of large size plasma apo(a) besides that which occurs via the intact $\mathrm{Lp}(\mathrm{a})$ particle.

Quantitative blotting analysis with specific probes has been used to determine genomic copy number in studies of Trisomy 21 (23). We believe that our report is the first application of this technique to determining the genetic basis of the concentration of a protein in plasma. The success of our technique is dependent on the choice of probes $(<72 \%$ homologous to plasminogen sequences) and the stringency of the washing conditions. We also selected a restriction enzyme Xba I that results in a very simple Southern blotting pattern. 


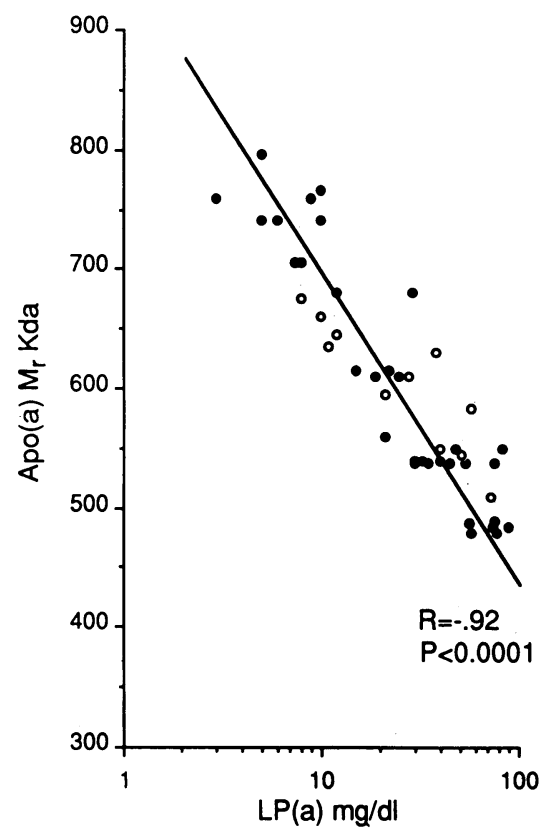

B

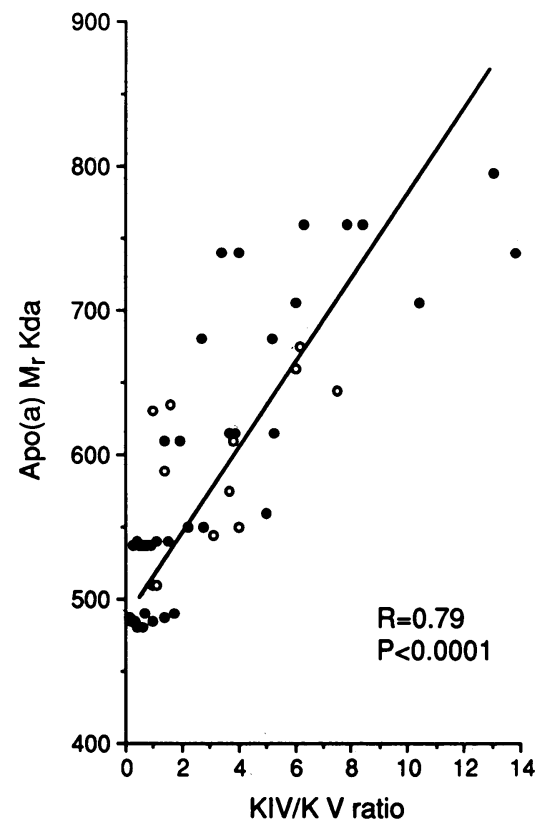

C

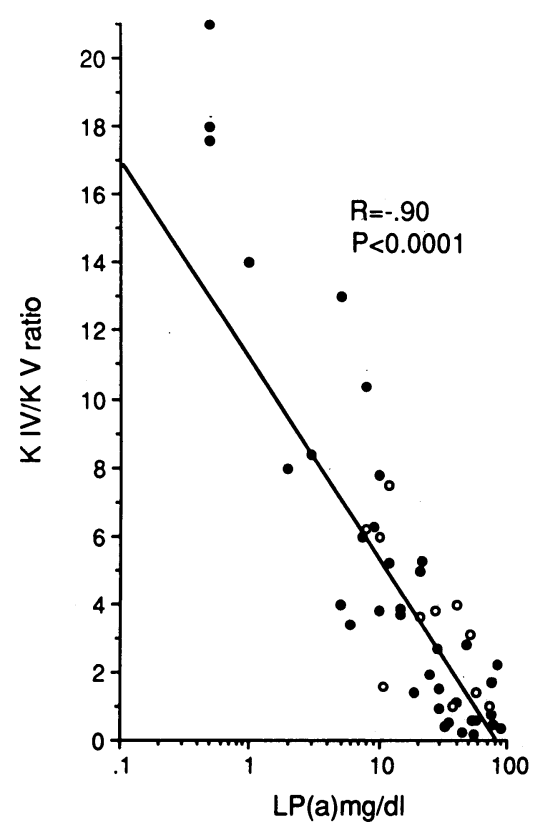

Figure 6. Linear regression analysis curves demonstrating the correlations between $(A) \log \mathrm{Lp}(\mathrm{a})$ level and apo(a) $M_{\mathrm{r}} ;(B)$ apo(a) $M_{\mathrm{r}}$ and $\mathrm{Krin}$ -

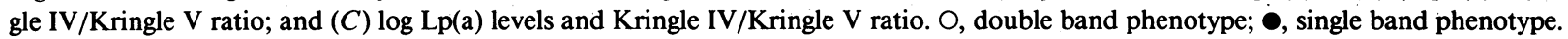

In the current study, we found a striking inverse correlation of $\mathrm{Lp}(\mathrm{a})$ level or $\log \mathrm{Lp}(\mathrm{a})$ level with the Kringle IV/Kringle $\mathrm{V}$ ratio $(-0.61$ and -0.90 , respectively). This suggests that the apo(a) gene structure itself plays the major role in determining plasma $\mathrm{Lp}(\mathrm{a})$ concentrations and is compatible with previous family studies that used linkage analysis, which arrived at similar conclusions $(9,12)$. However, the fact that the correlation coefficients observed were not one implies that factors other than the number of Kringle IV encoding domains are also important in determining plasma $\mathrm{Lp}(\mathrm{a})$ concentration.

In the current study, the degree of predictability of the plasma $L p(a)$ concentration by quantitative Southern blotting also reinforces the assessment from twin studies demonstrating the high heritability of $\mathrm{Lp}(\mathrm{a})$ levels (24). Interestingly, both sets of findings are in agreement with other studies that have found little influence of environmental variables, such as diet and drugs, on plasma $\mathrm{Lp}$ (a) concentrations $(25,26)$.

In summary, we provide evidence that apo(a) size and plasma $L p(a)$ levels are inversely correlated with the ratio of Kringle IV/Kringle $\mathrm{V}$ encoding domains in the apo(a) gene. Further studies are necessary to elucidate the exact mechanism responsible for this phenomenon.

\section{Acknowledgments}

This work was supported in part by grants from the National Institutes of Health (HL-36461, HL-32435, HL-21006 and CA-29502) and a General Clinical Research Grant (RR-00102). Dr. Jan L. Breslow is an Established Investigator of the American Heart Association.

\section{References}

1. Gaubatz, J. W., C. Heideman, A. M. Gotto, Jr., J. D. Morrisett, and G. H. Dahlen. 1983. Human plasma lipoprotein(a) structural properties. J. Biol. Chem. 258:4582-4589.
2. Fless, G. M., C. A. Rolin, and A. M. Scanu. 1984. Heterogeneity of human plasma lipoprotein(a) isolation and characterization of the lipoprotein subspecies and their apoprotein. J. Biol. Chem. 259:11470-11478.

3. Hoefler, G., F. Harnoncourt, E. Paschke, W. Mirtl, K. H. Pfeiffer, and G. M. Kostner. 1988. Lipoprotein Lp(a): a risk factor for myocardial infarction. Arteriosclerosis. 8:398-401.

4. Dahlen, G. H. 1988. Lipoprotein(a) in relation to atherosclerosis disease. Recent Aspects of Diagnosis and Treatment of Lipoprotein Disorders: Impact on Prevention of Atherosclerotic Disease. Alan R. Liss, Inc., New York. 27-36.

5. Utermann, G., H. G. Kraft, H. J. Menzel, T. Hopferweiser, and C. Seitz. 1988. Genetics of the quantitative Lp(a) lipoprotein trait. I. Relation of $\mathrm{Lp}(\mathrm{a})$ glycoprotein phenotypes to $\mathrm{Lp}(\mathrm{a})$ lipoprotein concentration in plasma. Hum. Genet. 78:41-46.

6. McLean, J. W., A. M. Scanu, and R. M. Lawn. 1987. cDNA sequence of human apolipoprotein(a) is homologous to plasminogen. Nature (Lond.). 330:132-137.

7. Eaton, D. L., G. M. Fless, W. J. Kohr, J. W. McLean, Q. T. Xu, C. G. Miller, R. M. Lawn, and A. M. Scanu. 1987. Partial amino acid sequence of apolipoprotein(a) shows that it is homologous to plasminogen. Proc. Natl. Acad. Sci. USA. 84:3224-3228.

8. Forsgren, M., B. Raden, M. Israelsson, K. Larsson, and L. O. Heden. 1987. Molecular cloning and characterization of a full length cDNA clone for human plasminogen. FEBS (Fed. Eur. Biochem. Soc.) Lett. 213:254-260.

9. Utermann, G., H. J. Menzel, H. G. Kraft, H. C. Duba, H. G. Kemmler, and C. Seitz. 1987. Lp(a) glycoprotein phenotypes. Inheritance and relation to $\mathrm{Lp}(\mathrm{a})$ lipoprotein concentration in plasma. $J$. Clin. Invest. 80:458-465.

10. Murray, S. C., K. H. Buetow, M. Donovan, S. Hornung, A: G. Motulsky, E. Giblett, E. Sadler, R. Eddy, and T. B. Shows. 1987. Linkage disequilibrium of plasminogen polymorphism and assignment of the gene to human chromosome 6q26-27. Am. J. Hum. Genet. 40:338-350.

11. Frank, S. L., I. Klisak, R. S. Sparks, T. Mohandas, J. W. McLean, J. E. Tomlinson, R. M. Lawn, and A. J. Lusis. 1989. Local- 
ization of the structural gene for lipoprotein(a). Am. J. Hum. Genet. In press.

12. Drayna, D. T., R. A. Hegele, P. E. Hass, M. Emi, L. L. Wu, D. L. Eaton, R. M. Lawn, R. R. Williams, R. L. White, and J. M. Lalouel. 1988. Genetic linkage between lipoprotein(a) phenotype and a DNA polymorphism in the plasminogen gene. Genomics. 3:230236.

13. Armstrong, V. W., A. K. Walli, and D. Seidel. 1985. Isolation characterization and uptake in human fibroblasts of an apo(a)-free lipoprotein obtained on reduction of lipoprotein(a). J. Lipid. Res. 26:1314-1323.

14. Ouchterlony, O. 1964. Gel diffusion techniques. In Immunological Methods. J. F. Ackroyd, editor. Blackwell Scientific, London. 55 .

15. Laurell, C. B. 1986. Quantitative estimation of proteins by electrophoresis in agarose gel containing antibodies. Anal. Biochem. 15:45-49.

16. Laemmli, U. K. 1970. Cleavage of structural proteins during the assembly of the head of bacteriophage T4. Nature (Lond.). 227:680-684.

17. Towbin, H., T. Staehelin, and S. Gordon. 1979. Electrophoretic transfer of proteins from polyacrylamide gels to nitrocellulose sheets: procedures and some applications. Proc. Natl. Acad. Sci. USA. 76:4350-4358.

18. Grunning, P., P. Ponte, H. Okayama, J. Engel, H. Blau, and L. Kedes. 1983. Isolation and characterization of full-length cDNA clones for human $\alpha$-, $\beta$ - and $\gamma$-actin mRNAs: skeletal but not cytoplasmatic actins have an amino-terminal cysteine that is subsequently removed. Mol. Cell. Biol. 3:787-795.
19. Southern, E. M. 1975. Detection of specific sequences among DNA fragments separated by gel electrophoresis. J. Mol. Biol. 98:503-517.

20. Gaubatz, J. W., K. I. Ghanen, J. Guevara, M. L. Nava, and J. D. Morriset. 1988. Relationship of apo(a) polymorphs to plasma levels of apoproteins and lipids and to mode of inheritance. Lipoprotein(a); 25 years of progress: Meeting. Abstract. 1 December 1988, Chicago, IL.

21. Goldberg, A. L., and A. C. St. John. 1976. Intracellular protein degradation in mammalian and bacterial cells: part 2. Annu. Rev. Biochem. 45:748-791.

22. Bersot, T. P., T. L. Innerarity, R. E. Pitas, S. C. Rall, Jr., K. H. Weisgraber, and R. W. Mahley. 1986. Fat feeding in humans induces lipoproteins in density less than 1.006 that are enriched in apolipoprotein(a) and that causes lipid accumulation in macrophages. J. Clin. Invest. 77:622-630.

23. Dahl, H. H. M., K. H. Choo, and D. M. Danks. 1988. Application of DNA-DNA hybridization of dual labeled probes to the detection of trisomy 21 , monosomy 21 , and sex determination. Am. J. Hum. Genet. 43:502-510.

24. Berg, K. 1987. Twin studies of coronary heart disease and its risk factors. Acta Genet. Med. Gemellol. 36:439-453.

25. Kostner, G. M. 1988. The affection of lipoprotein(a) by lipid lowering drugs recent aspects of diagnosis and treatment of lipoprotein disorders: Impact on prevention of atherosclerotic disease. Alan R. Liss, Inc., New York. 255-263.

26. Guraker, A., J. M. Hoeg, G. Kostner, N. M. Papadopoulos, and H. B. Brewer, Jr. 1985. Levels of lipoprotein Lp(a) decline with neomycin and niacin treatment. Atherosclerosis. 57:293-301. 